\title{
Information needs and information seeking behavior of parliamentarians in South Africa
}

\author{
B.J. Mostert \\ jmostert@pan.uzulu.ac.za \\ Dennis N. Ocholla ${ }^{2}$ \\ docholla@pan.uzulu.ac.za
}

Department of Library and Information Science, University of Zululand,
Private Bag XI00I KwaDlangezwa, 3886., South Africa

Recieved: $10^{\text {th }}$ November 2004
Revised: $2^{\text {nd }}$ December 2004

Key words: Information Needs; Information Seeking Behaviour; Farliamentarians; South Africa

Parliamentarians have an incessant need for timely, authoritative, and current information because of the enormous social responsibility bestowed on them by the electorates or society. A strong information accessibility that empowers them to fulfill this responsibility effectively is therefore very significant. Essentially and traditionally, parliamentary libraries are expected to provide legislators with most of the information they need. The study aimed at determining the information sources, service and systems used in South Africa by the parliamentarians, and also to investigate the role of the parliamentary libraries in the information provision process. A survey was conducted by use of questionnaires targeting all parliamentarians in South Africa and a response rate of $23 \%$ (167) was received. This study has revealed that parliamentary libraries are underutilized because parliamentarians use other equally competing information sources largely accessed through the internet. Further, South Africa has enormous information sources and services that legislators can access and exploit and the use of electronic sources of information is growing rapidly, almost reaching the level of use of print sources. Unexpectedly, oral sources of information are used less. Parliamentary libraries have a potential to offer a variety of services to parliamentarians, yet they are not well-utilized, perhaps because of reasons such as poor marketing and innovative information services. Wilson's model on information seeking has been extended by a new model proposing and explaining information-seeking strategies popular to parliamentarians in South Africa.

\section{Introduction}

The aim of the study was to investigate the parliamentary information sources, systems and services in South Africa and determine the role that is played by parliamentary information services in the country. This involved exploring the various sources, services and systems used to access information, determining if parliamentarians do access and utilize traditional information sources and systems such as the parliamentary library services to satisfy their information needs, investigating the degree of Internet and e-source utilization in the information gathering and exploitation process, investigating the services of the traditional parliamentary library to determine its capacity to provide efficient information services to the parliamentarians and proposing recommendations and suggesting a conceptual model for effective parliamentary information services.

The lack of a unifying body of knowledge in LIS is lamented by many Library and Information Science (LIS) scholars (e.g. Dervin and Nilan 1986; Itoga 1992; Krikelas 1983; Hjørland 1998; Van Lill 2000). Some such as Busha and Harter (1980) ascribes this gap to practice rather than theory orientation of information work or librarianship, while others blame the fragmentation of literature on user studies, as well as its superficial nature to have made it difficult to draw meaningful conclusions and support a unified theory (Rohde, 1986). Both Kulthau (1993) and Van Lill (2000) lament that Information Science is currently in a theory building phase with traditional conceptual frameworks being revisited and new perspectives proposed. Although the traditional viewpoint (Smith 1991, Van Lill, 2000) has always viewed information as a product of human invention or symbolic representations of reality, a lot of attention tends to be given to alternative/cognitive viewpoint that focuses on the user, be it as recipient or producer of information. In this instance the existing knowledge base, values, beliefs influence what a person perceives, receives or produce. Central to the formation of perceptions is the allocation of meaning to the information received, as well as the context in which the human finds

I. Janneke Mostert, PhD, is a senior lecturer in the Department of Library and Information Science, University of Zululand, South Africa

2. Dennis Ocholla, PhD, is a professor and head of the Department of Library and Information Science, University of Zululand, South Africa. 
himself (Belkin 1990). Stonier (1991) agrees with this viewpoint, adding that information only becomes meaningful should it be analyzed, compared and integrated with existing information within the perceiver's system. By attaching meaning to information it becomes a contributor towards problem solving and decision-making (Boon 1992).

McCreadie and Rice (1999) provide a strong concise overview of the current conceptualizations of information. According to them there are currently four major assumptions about information, Firstly, information as commodity $/$ resource. Information is seen as a physical commodity to be "produced, purchased, replicated, distributed, manipulated, and passed along, controlled, traded and sold" (1999:46). Buckland (1991) advocates that information-as-thing is always situational, and that the information value of a given piece of information can differ from situation to situation. Parliamentarians need access to all kinds of information, be it freely available in the public domain, or only accessible at a price. From the perspective of their role as information providers and gatekeepers to their constituents they can also be observed as producers, manipulators and communicators of information. Secondly, Information as data in the environment. This conceptualization sees information as including the data available from an individual's environment. This data can be communicated intentionally or unintentionally for human processing, and can be gained from objects, artifacts, sounds, smells, visual and tactile phenomena, events or phenomena of nature. By the nature of their work parliamentarians need to observe their environment for meaningful decision-making. Some portfolios in Government require that parliamentarians make observations from their environment, for example agriculture, safety and security, water affairs, and environmental affairs. In many cases information gained through observing objects, artifacts, acts of nature, can provide the necessary information for decision-making. Thirdly, Information as a representation of knowledge. Information is viewed as "a representation of, or pointer to, knowledge" (McCreadie \& Rice 1999:48). The printed document like books, journals, citations, and so on, is assumed to be the primary representation of knowledge. Recent technological advances in the electronic media have provided alternative options as primary representatives. From the viewpoint of information representation, in whichever format information is presented, representations are seen as the sources of information. Parliamentarians make use of both formal and informal information systems and services to gain information. Within the formal systems it would be assumed that the written document is the preferred medium of communication of information. Fourthly, information as part of the communication process. Meanings are seen to be in people rather than in words or data. A variety of factors like timing, social factors and personal factors influence the processing and interpretation of information. When interpreting and evaluating information, the context, be it geographical, social, educational, professional, and so on, will influence the understanding of the message (Madden 2000; Wilson, 1999). Parliamentarians are confronted on a daily basis with information gained through different means. Interpretation and evaluation of the messages received can lead to a continual process of rejection or acceptance of that information. Both these reactions should lead to actions, either of repeating the search for information or by internalizing and acting on the knowledge gained.

We recognize that how information is found and used has for long been a major focus point in the field of Library and Information Science, resulting in extensive developments in the last few decades (Leckie, Pettigrew and Sylvian 1996). Several general models concerning information need and seeking have been developed in the last few decades, notably that on information need (Krikelas, 1983), information seeking (Ellis, 1989; Wilson, 198I, 1997, 1999; Kulthau, 1991) and information retrieval (Ingwersen 1992, 1999). Ellis's model laid the foundation for determining the different steps taken during the information seeking process that includes six steps in the process. Thus, starting, chaining, browsing, differentiating, monitoring and extracting, with two more features added during later studies, thus, verifying and ending and filtering and proposed that this model could be used for studying both conventional and electronic sources (Turnbull n.d.). We however found the general model as proposed by Wilson in 1999 quite comprehensive for examining information behavior of parliamentarians. Wilson (1999) describes a model as "a framework for thinking about a problem and may evolve into a statement of the relationships among theoretical propositions" (1999:250). In his opinion the majority of models currently available tend to be in a pre-theoretical stage concentrating on diagrammatical descriptions of statements, indicating causes, factors, and consequences, rather than concentrating on the theoretical stage where relationships among theoretical propositions are described. Wilson (1997) claims that a general model can be constructed supporting the needs of all the respective disciplines.

Despite these early efforts, Wilson conceded that this effort in model building was mainly aimed at identifying and showing the gaps to be researched. He later (1999) proposed a general model of information seeking behavior which tended to embrace our thinking of the environment on information behavior of parliamentarians in South Africa. 


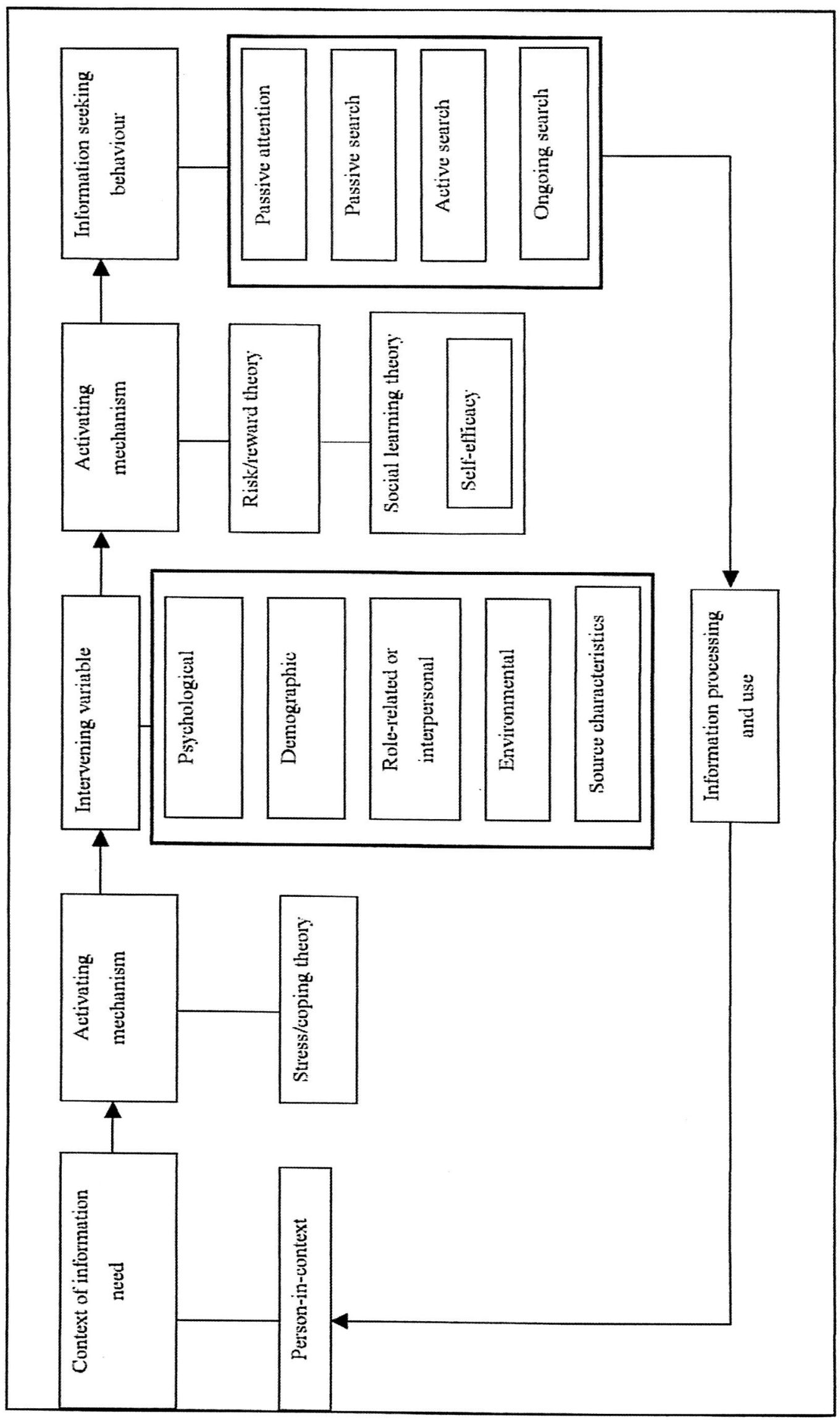

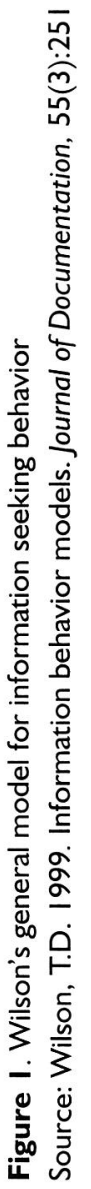


We have, however, noted that given the time constraints within which the parliamentarians operate the model does not allow for the utilization of a third party as an information mediator in the information acquisition process. The third party operates as a go-between the parliamentarian with his information need and the information source, system or channel utilized to acquire and access the information. In the critique of the information-seeking models Gross (200I:I) comes to the conclusion that: "the majority of these models assume that individuals seek information and interact with information systems in response to their own, self-generated needs. While these models do recognize that people go to other people as potential resource when in pursuit of information, the models fail to recognize that the default behavior, when the person doesn't have the answer, doesn't have to be an interaction with information providing objects, organizations or systems. Instead the person seeking information may ask someone to find the answer for them"

\section{Research procedure}

The study targeted all parliamentarians and parliamentary libraries in South Africa. A survey amongst the parliamentarians focused on parliamentarians of all ten legislatures in the country. Of the 763 parliamentarians in the country at least 33\% of them are women. Parliamentarians attend either the National Assembly meetings in Cape Town or the Provincial Legislative sessions/meetings in their respective legislative capitals. Any person over the age of eighteen is eligible to be elected as a representative with no age restriction on retirement. No educational or professional limits are set, thus anybody regardless of educational level is likely to be put on the party lists.

For the survey concerning the parliamentary libraries the chief librarians of all the parliamentary libraries in South Africa were targeted. A survey through self- administered questionnaires was used to gather data from all the parliamentarians, both in the National Assembly and the Provincial Legislatures, as well as all the parliamentary libraries in South Africa. This enabled the study to determine their attitudes towards information sources and channels, as well as opinions about the services rendered to them by their parliamentary libraries. The main reason for the choice of survey and questionnaires was mainly because of the wide distances between each of the parliaments, as well as factors such as difficulty in accessing all prospective respondents during a specific timeframe. We noted that due to their busy work schedules, as well as for security reasons, access to individual parliamentarians within their work environment was virtually impossible. Respondents were scattered throughout all nine provinces. The financial implications also played a role in the decision, as this method is seen as the cheapest type of survey, requiring no field staff, thus no transport and other costs (Hagan 2000). A final consideration was that it was assumed that the respondents were literate and that their educational level was such that they could complete the questionnaire without researcher assistance. This was an important consideration as it became clear early on that research assistants from outside would not be allowed to conduct the survey personally.

The questionnaire for parliamentarians solicited information on:

- personal information e.g. educational level, political affiliation, position held in party politics, provincial representation, and ability to access Internet.

- Information needs and searching strategies e.g. what, why, how, when information is needed and search strategies followed to find information, and problems concerning electronic sources utilization;

- Institutions used to find information focused on determining what. channels parliamentarians use to find information, both on a national level and internationally. Specific questions concerning parliamentary library, and the research section utilization was been asked to determine whether they play a role at all in information provision to parliamentarians.

The questionnaire for parliamentary libraries focused on:

- background information to determine information concerning the establishment of the library, as well as the physical layout of the building,

- staffing and service structure;

- information products and services offered by the Library/Research service with an aim to ascertain whether the services/products offered were comparable to those offered in other parts of the world and also to determine weaknesses and strengths in the service provision;

- Developments in automation e.g. the level of services automation, internet access, as well as access to electronic databases and on important developments in Library/Research services in the library required libraries to expand on any recent developments of note that took place or anything new or planned. As it is required from parliamentary libraries to move with the changing times, this section aimed at establishing whether it was indeed happening. Observation supplemented the self-administered questionnaire for the Parliamentary Libraries. Observations were done by one of the authors at the Parliamentary Library in Cape Town. The observer made use of the non-participant passive observation method. The main function of the observer was merely to record the data (Sarantakos 1998). A checklist was used to gather information. The checklist concentrated on items such as the physical appearance of the building, 
directions to and inside the library, the inside appearance of the library and coliection and service delivery. The data provided more information on issues not covered in the questionnaire, or issues that could be better described once observed firsthand, e.g. the actual service delivery to Parliamentarians, state of collection available for service delivery, whether the atmosphere was conducive, building of relationships with parliamentarians, and the appearance of the library. Literature review helped as Neuman (2003) put it to build on, and learn from, already existing knowledge. Documentary sources were used to review issues related to parliamentary library services, parliament and its functioning, democracy and its historical developments worldwide, but also specifically in South Africa. It was also used to determine the extent of information sources available to parliamentarians in South Africa. A major source of information, especially on parliamentary libraries and their functioning was the conference papers available on the IFLA website. This provided valuable insight into the latest developments in this specialized information service and proved helpful in benchmarking the South African Parliamentary Library services. The Internet was used extensively in the search for documents, and proved helpful in finding materials on a wide range of topics covered in the study. Annual reports obtained from the Parliamentary Library in Cape Town, as well as a special report obtained from the librarian of the KwaZulu-Natal Provincial Parliamentary Library proved useful in providing background information on the history, developments and current status of the South African Parliamentary Libraries. Studies on topics like information-seeking behavior and information-seeking models, as well as democracy and South African history were reviewed. It was noted that on their own document sources can't adequately supply all the answers to questions raised through research, and must be seen as complementary to the study, providing the researcher with a theoretical framework for gaining information to form new opinions, judgments or applications of knowledge.

Permission to do the study was sought from all ten Legislatures in South Africa. Letters were addressed to the Speakers of Parliament. Reaction from these Offices varied, from very prompt to having to repeat the request several times. Eventually nine out of the ten Legislatures responded. The Eastern Cape Legislature did not respond at all, despite several efforts to get permission. Once permission was secured the questionnaires were sent to a person appointed by the Speaker to liaise with the researcher (This only applied for the Provincial Legislatures). The National Parliament Office of the Speaker, although giving permission, did not want to be involved in any way. In this case a visit to the National Assembly was made, and with the assistance of the Chief Librarian of the Parliamentary Library had the questionnaires delivered through the internal mailing system. A research assistant from the University of Stellenbosch was responsible for follow-up work. Each questionnaire was addressed personally to each parliamentarian, and included a self-addressed return envelope. The questionnaires were distributed through the internal mailing system of each Legislature. The first batch of questionnaires was sent in mid-March 2002 and the last batch in August 2002. Respondents were given a period of three weeks to respond to the questionnaire. Follow-up work was done by way of letters. In the National Assembly the research assistant tried to follow a more direct approach by contacting parliamentarians individually, but was not allowed to continue by the security staff.

A total of 763 questionnaires were sent out and the response rate was $167(23 \%)$. Although this is considered to be low, we found this to be in line with response rates for similar studies done both nationally and internationally, for example a study done by the Library of Parliament in Cape Town in 1996, initially had a response rate of $12.5 \%$. As it was found to be too low, the study was extended and intensive follow-up work done. This resulted in a final response rate of $20 \%$ (Research findings of Library Questionnaire 1997). In a similar study done at the North West Provincial Legislature the return rate was $14 \%$. Thapisa (1996) had a return rate of $27 \%$ in his study done in Botswana. A study amongst parliamentarians of the Uganda Parliament was abandoned because of a return rate of $11 \%$. Marcella, Carcary and Baxter (1999) reported a response rate of $34 \%$ in a study done amongst parliamentarians representing the United Kingdom in the European Parliament.

Questionnaires for each library were included with each batch of questionnaires sent to the parliamentarians. Followup work was done with letters.

Analysis was done using an Excel spreadsheet to record and store the data, and the Ms Access database was used to extract the information to be analyzed. For the purpose of doing the quantitative analysis the variables used were coded numerically. Multivariate analysis, i.e. the explanation of a dependent variable through the use of more than one independent variable, was used. Analysis of data from observation was categorized based on the following themes: external appearance of the library building, the inside appearance of the library, staff behavior in the library, space and seating capacity within the library, guidance to library use and directional signage.

The study presented many problems and challenges to overcome. A major problem was the non-responsiveness from both the respective offices of the Speakers, as well as the respondents. From the perspective of the relative "seclusion", as well as the geographical dispersion, in which the respondents operate, it presented a very real problem to elicit responses from the respondents. Every effort was made to have follow-up procedures in place, for example, contact 
people in the provincial legislatures were asked to do some follow-up work, which unfortunately was also not always possible due to their heavy workload. The Speaker's personal sanction of the studies were sought in the hope that it would illicit more responses, and in the case of the National Assembly in Cape Town, a research assistant was employed, only to be deterred from doing personal follow-up work.

Being geographically so dispersed also proved too costly for us to visit each legislature in person, which could have given more insight into the functioning of each specific provincial legislature. This could have led to a much more complete picture.

Within parliamentary libraries the study was also sometimes deemed with some suspicion, and therefore it could have influenced the way in which the questionnaire was answered. Personally contacting the librarians and explaining the reason for the study mostly overcame the problem.

\section{Discussion of the results of the study}

\section{I Information sources, services and systems}

South Africa has a strong and rapidly growing information sector in Africa that comprises libraries, bookstores, publishing houses dating back to 1824 (see Muller 1968) newspapers (see http://www.iol.ac.za) internet connectivity, widely a available to parliamentarians and the public. The legal deposit law that obliges all publishers to deposit copies of their publications in the five Legal Deposit Libraries, of which the Library of Parliament in Cape Town is also in favour of parliamentarians who are the main users of parliamentary library.

Information accessibility to all South Africans has significantly improved since 1994. For example, public libraries are available in the majority of townships, cities and towns throughout the country. Though physical access to the information sources in the libraries is not always feasible, the South African Interlending System and the SABINET online system, both subscribed to by the parliamentary libraries, provide access to the collections of the majority of libraries in southern Africa (Behrens 2000).

Technology has changed the information landscape worldwide. South Africa, being one of the major utilisers of the Internet in the world, can boast modern technology and networks providing access to a wide variety of electronic information sources such as on-line bookshops, newspapers, journals and databases, parliamentary websites, both local and international, reference source materials such as dictionaries and encyclopedia, and webpages containing information on a myriad of topics and organizations.

The study found that Internet access is widespread amongst the parliamentarians as $78 \%$ had access to networked computers, either at home or in the office. Actual utilization of this source was rated at $63 \%$. Taking into account that electronic information sources, such as the Internet were introduced to the general South African public only within the last decade, this is a good reflection of the widespread availability and utilization of information technology, as well as to the adaptability of humankind. Compared to the 14\% Internet access and utilization in Ghana (Alemna and Skouby 2000), and $73 \%$ by the Members of the House of Commons, United Kingdom (Serema 1999), Internet utilisation by South African parliamentarians is relatively high. Although government's commitment to the advancement of the status and availability of technology is commendable, problems related to low bandwidth inadequate or faulty technology, lack of both computer and information seeking skills is experienced as a major contributor to under-utilization of technology.

3.2 Trends in information source utilization by parliamentarians

As demonstrated in the previous section, information is available and can be accessed through a variety of sources, services and systems. Familiarity with the source/system might influence selection, though the kind of information contained in the source might also influence choice. The results are indicated in Table I.

Various studies done amongst parliamentarians indicated a preference for print-based sources (e.g. Orton, Marcella and Baxter 2000). This study concurs with those studies indicating that traditional sources such as books, journals, newspapers and governmental publications are still more preferred information sources amongst parliamentarians. Both familiarity with the sources, easy access and use whenever needed plays a big role in its ultimate choice. Newspaper utilization seems to the premium source preferred as only 10\% of the respondents indicated that they never use newspapers. Issues of the day seem to be important. Governmental publications provide information on current policies and activities of government therefore it could have been expected to be well utilized. The use of such sources proved to be relatively high with $60 \%$ of the parliamentarians using them often. 
Table I Information sources/systems used

$\mathbf{N}=167$

\begin{tabular}{|c|c|c|c|c|c|c|c|c|c|}
\hline Sources/systems & Often & $\%$ & Seldom & $\%$ & Never & $\%$ & No Response & $\%$ & Total \\
\hline \multicolumn{10}{|l|}{ Print-based sources } \\
\hline Books & 109 & 65 & 28 & 17 & 24 & 14 & 6 & 4 & 167 \\
\hline Journals & 80 & 48 & 39 & 23 & 42 & 25 & 6 & 4 & 167 \\
\hline Newspapers & 133 & 80 & 11 & 7 & 17 & 10 & 6 & 4 & 167 \\
\hline Magazines & 80 & 48 & 40 & 24 & 41 & 25 & 6 & 4 & 167 \\
\hline Governmental publications & 101 & 60 & 33 & 20 & 27 & 16 & 6 & 4 & 167 \\
\hline \multicolumn{10}{|l|}{ Electronic sources } \\
\hline Internet & 84 & 50 & 22 & 13 & 55 & 33 & 6 & 4 & 167 \\
\hline Digital libraries on the Internet & 30 & 18 & 32 & 19 & 99 & 59 & 6 & 4 & 167 \\
\hline Virtual libraries on the Internet & 20 & 12 & 29 & 17 & 112 & 67 & 6 & 4 & 167 \\
\hline On-line databases & 25 & 15 & 25 & 15 & 111 & 66 & 6 & 4 & 167 \\
\hline Electronic journals on the internet & 73 & 44 & 33 & 20 & 55 & 33 & 6 & 4 & 167 \\
\hline Electronic newspapers & 62 & 37 & 38 & 22 & 61 & 37 & 6 & 4 & 167 \\
\hline \multicolumn{10}{|l|}{ Information systems } \\
\hline Government Departments & 79 & 47 & 47 & 28 & 35 & 21 & 6 & 4 & 167 \\
\hline NGO's & 44 & 26 & 58 & 35 & 59 & 35 & 6 & 4 & 167 \\
\hline Parliamentary library & 56 & 34 & 56 & 34 & 49 & 29 & 6 & 4 & 167 \\
\hline Public library & 18 & 11 & 51 & 31 & 92 & 55 & 6 & 4 & 167 \\
\hline Embassies & 16 & 10 & 44 & 26 & 101 & 60 & 6 & 4 & 167 \\
\hline National archives & 15 & 9 & 43 & 26 & 103 & 62 & 6 & 4 & 167 \\
\hline \multicolumn{10}{|l|}{ Oral sources } \\
\hline Parliamentary colleagues & 57 & 34 & 44 & 26 & 60 & 36 & 6 & 4 & 167 \\
\hline Individuals in the private sector & 40 & 24 & 52 & 31 & 69 & 41 & 6 & 4 & 167 \\
\hline Individuals in the public sector & 45 & 27 & 41 & 25 & 75 & 45 & 6 & 4 & 167 \\
\hline Chiefs/indunas & 11 & 7 & 21 & 13 & 129 & 77 & 6 & 4 & 167 \\
\hline
\end{tabular}

The utilization of electronic sources has been surprisingly high. In an unpublished study done by the Library of Parliament in 1997 it was found that the median age level of parliamentarians was from $40-60$, indicating a generation not exposed to electronic information sources. Despite this non-exposure, respondents seem to have taken advantage of the availability of the source in their work or home environment, and developed their own searching strategies for utilizing the source. The sources providing updated, full-text documents/information such as e-news and e-journals were well utilized. It was found that portals giving access to a variety of local or international newspapers or journals were preferred. The e-news-websites also offered the additional option of classifying news according to subject categories, saving time and effort. The availability of e-news archives lead to their utilization in some cases.

Findings indicated that time were a very big factor influencing Internet utilization. Complaints about slow technology, insufficient time to search effectively, and too many references to sift through were observed. These are common to many Internet users, but given the time constraint, under which parliamentarians are operating, these factors can form a huge barrier to information accessibility.

The low utilization of on-line databases, digital and virtual libraries can probably be attributed to ignorance about their existence, but also to the fact that in many cases a membership fee has to be paid.

Legislative libraries function within the immediate work environment of the parliamentarians. However, the study found that legislative libraries are under-utilized as only $34 \%$ of the legislators indicated that they use the legislative libraries often. This situation raises concerns about the effectiveness of the services offered, whether marketing strategies are adequate and whether innovative services are rendered 
An assumption made in the study was that the oral tradition is still widely used as a means of seeking information. Thapisa (1996) describes it as a major source of information gathering amongst parliamentarians in Africa. However, in this study oral sources are not as highly valued as anticipated. A possible explanation could be the ready availability of many other sources of information. The information rich environment provides many alternatives that act as reliable and easily accessible sources. Seeking advice from an oral source can be a time consuming process, especially if it is a source from outside the immediate work environment.

It was observed that whereas the majority of parliamentarians still prefer to receive their information in hard copy format $(74 \%)$, an equal preference was expressed for information in a digital or electronic format $(60 \%)$. The preference for oral communications was $14 \%$, indicating a significant swing from the oral tradition. It could be argued that the preference for either print or digital format is influenced by increased preference for information that can be accessed at any time.

It was revealed that the majority of parliamentarians (75\%) obtain their information using their own personal sources. unfortunately; we did not aim to determine the nature of these sources. The quality of the personal sources could also not be ascertained. However, it is the opinion of the authors that parliamentarians should be encouraged to use professionally verified information, especially where it concerns information used for legislative activities that affect the entire nation. Notably, own searching of information is confirmed by $62 \%$ rating indicating that other than using their own personal sources, they obtain information by using their own PC. The growing utilization of computers for information searching must be viewed as both a threat and an opportunity to formal information systems such as the legislative libraries. The threat lies in the demise of the library as traditional information provider. The opportunity however should be seen in the extension of the horizon of information services b exploring and exploiting all forms of value-added services that would invite new forms of repackaging information.

\subsubsection{Role of education in information source/system utilization}

Although a large number of parliamentarians lacked educational opportunities and was provided with a very low educational standard in the past, the responses received portrayed a very different picture emerged, revealing a fairly highly educated group of people with very few not in possession of at least a school-leaving certificate. This is contrary to the findings by Thapisa (1996), who reveals that the majority of African parliamentarians have not moved beyond a basic education, but in correlation with a study done by Alemna and Skouby in Ghana (2000).

Doing a cross-tabulation of the results, using the "often" choice as an indicator, it was found that parliamentarians with a high educational level diversified their information sources and Respondents with a Matric and higher in general made use of all the information sources and systems mentioned in the study, while those in possession of a Grade 10 qualification availed themselves of only 12 of the available options, noticeably with the print options as well as some of the electronic options. Familiarity with an information source plays a big role in its ultimate preference, especially within less educated groups. Within the strong text-based educational environment that has been in existence in South Africa for many decades, familiarity with printed information sources is to be expected. Even the electronic sources utilized within this group, i.e. electronic journals and electronic newspapers have their familiar printed counterparts, thus making it a familiar source of information. Respondents in possession of a Grade 8 only used 5 options. This led to the assumption that a close relationship exists between exposure to information sources during formative years and the utilization thereof. Table 2 provides insight into the relationship between education and the utilization of information sources.

\subsection{Information needs and information seeking strategies}

Information seeking is an action taken in order to satisfy an information need. Information need has been described as an inadequacy or a gap in an individual's knowledge (Belkin, Oddy and Brooks 1982). To bridge the gap, and satisfy the information needs, action is required.

\subsection{Search strategies}

Ideally, parliamentarians function within a very information intensive environment. Parliaments' functions and activities are conducted within decision making in committees, rather than in the National or Provincial Assemblies. Decisions taken at Committee level are reported and approved at full parliamentary sessions. 
Table 2 Relationship between level of education and information source utilization $(n=167)$

\begin{tabular}{|c|c|c|c|c|c|c|c|}
\hline Sources & $\begin{array}{l}\text { Post-graduate } \\
\text { degree }\end{array}$ & $\begin{array}{l}\text { Under- } \\
\text { graduate }\end{array}$ & Diploma & Certificate & $\begin{array}{l}\text { Grade } 12 \\
\text { (Matric) }\end{array}$ & Grade 10 & Grade 8 \\
\hline \multicolumn{8}{|l|}{ Print-based sources } \\
\hline Books & 47 & 26 & 18 & 3 & 11 & 1 & 2 \\
\hline Journals & 31 & 22 & 15 & 2 & 8 & 1 & \\
\hline Newspapers & 47 & 35 & 28 & 6 & 14 & 2 & \\
\hline Magazines & 31 & 25 & 14 & 2 & 7 & I & \\
\hline Governmental publications & 39 & 27 & 16 & 3 & II & 2 & 2 \\
\hline \multicolumn{8}{|l|}{ Electronic sources } \\
\hline Internet & 31 & 20 & 19 & 5 & 8 & I & \\
\hline Digital libraries on the Internet & 14 & 7 & 4 & 2 & 3 & & \\
\hline Virtual libraries on the Internet & 10 & 4 & 2 & 3 & 1 & & \\
\hline On-line databases & 20 & 5 & 5 & 2 & 3 & & \\
\hline Electronic journals on the internet & 30 & 18 & 14 & 3 & 5 & 2 & \\
\hline Electronic newspapers & 47 & 21 & 28 & 6 & 14 & 2 & \\
\hline \multicolumn{8}{|l|}{ Information systems } \\
\hline Government Departments & 29 & 21 & 14 & 3 & 9 & 2 & I \\
\hline NGOs & 17 & 12 & 9 & 1 & 4 & 1 & \\
\hline Parliamentary library & 17 & 16 & 12 & 2 & 7 & । & I \\
\hline Public library & 7 & 6 & 4 & & I & & \\
\hline Embassies & 9 & 2 & I & & 3 & 1 & \\
\hline National archives & 5 & 5 & 2 & 2 & 1 & & \\
\hline \multicolumn{8}{|l|}{ Oral sources } \\
\hline Parliamentary colleagues & 14 & 17 & 12 & 2 & 11 & & I \\
\hline Individuals in the private sector & 15 & 9 & & 10 & 1 & 5 & \\
\hline Individuals in the public sector & 14 & 11 & 13 & 2 & 5 & & \\
\hline Chiefs/indunas & 3 & 1 & 3 & 1 & 3 & & \\
\hline
\end{tabular}

The findings indicated that the majority of the respondents (70\%) conducted their own searches. These findings concur with studies reported by Marcella, Carcary and Baxter (1999). However, the higher levels of the government hierarchy were exceptions, as they preferred not to search on their own, but rather use their personal assistants to do it for them. This choice was also exercised by $52 \%$ of the respondents. Whether the assistants are able to interpret their information need and are familiar with the search strategies, or use intermediaries was not determined in the study.

It is surprising that the researchers (35\%) and librarians (33\%) are an under-utilized group in information searching. Under-utilization of the information provider could be attributed to under-staffed library/research units, or ignorance of their functions and the effective interaction between the information provider and parliamentarians. It can also be argued that time constraints could be a mitigating factor.

\subsubsection{Nature of the information needs}

Though it was found that a variety of information needs are experienced, major needs could be distinguished. As could be expected topics concerning political issues or governance were given the highest priority. These could be seen as longterm information needs. The multiple other needs expressed corroborate with findings in studies done that the needs of the parliamentarians are wide and many (Kimbunga 1996; Thapisa 1996; Marcella, Carcary and Baxter 1999). This shorter term needs seem to be related to the portfolio position of the parliamentarian, or as a special interest area for knowledge expansion. The majority of the respondents indicated multiple needs giving an indication that their interests were broad. 


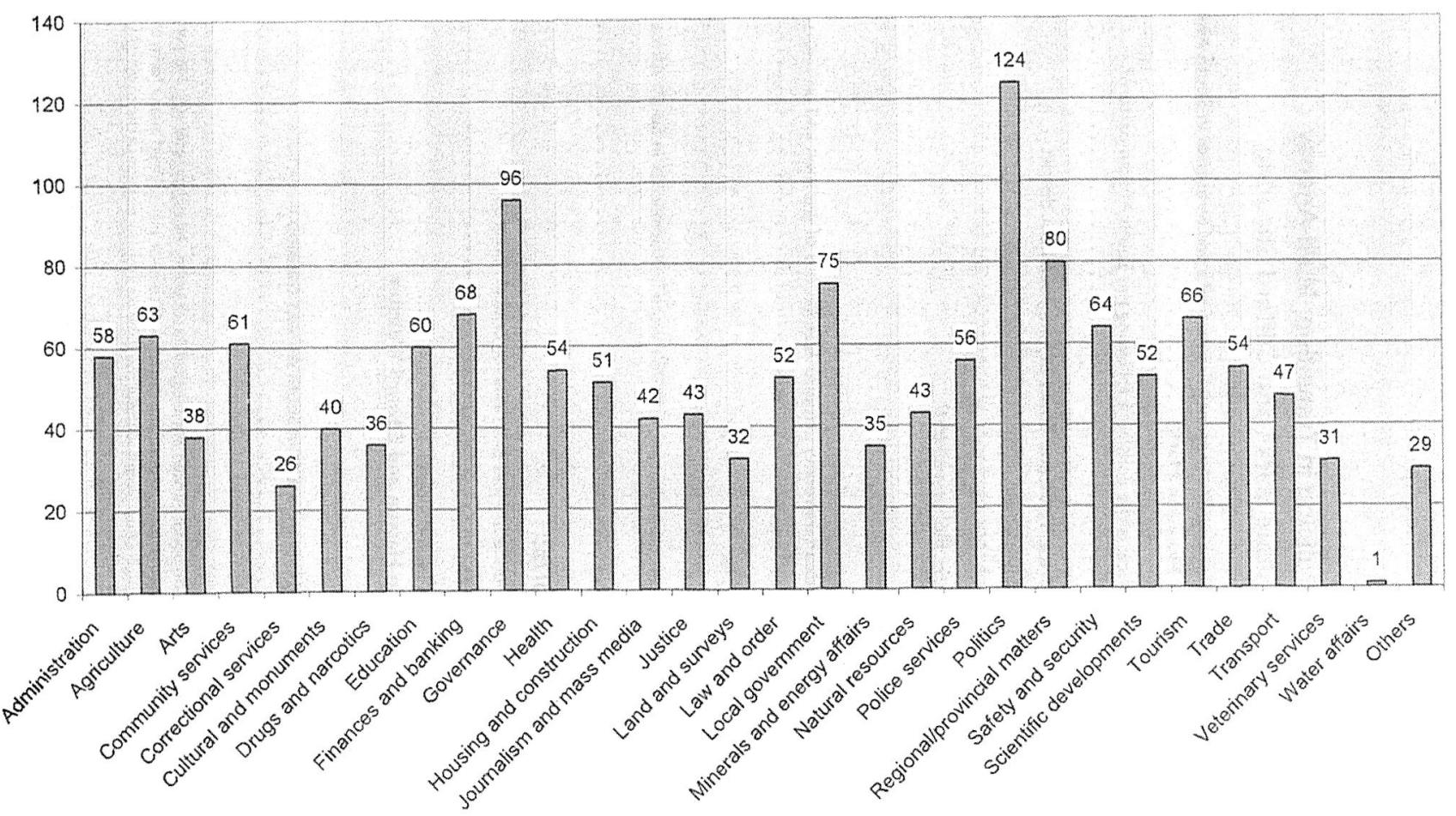

Figure 2 Information needs $\mathrm{N}=167$

\subsection{Role of the Legislative Libraries in the information delivery process}

As a formal information system the legislative libraries are the closest at hand for parliamentarians in all the provinces. It has been found that all the libraries are within close proximity of the work environment of the parliamentarians making them easily accessible options to use.

\subsection{Background}

With the exception of the Library of Parliament, Cape Town, with a history spanning nearly 150 years, all the provincial legislative libraries are newly established institutes, most not older than a decade. The majority has been established as a result of the introduction of a nine-province system, replacing the previous four provinces. With no local model to build on, other than the Library of Parliament it could be expected that they would have to rely on the Library of Parliament for guidance. It was found that it does not necessarily seem to be the case. Other than the occasional Research and Information Cluster meetings held on a rotating basis at the different legislatures, the libraries have to rely on themselves for capacity building. Though the mandate of these meetings is to learn "best practices" from each other this does not seem to fully materialize, with the result that many of the libraries seem to operate on their own. Compounding the problems is the fact that the role of the library is not always fully understood by their supervisory departments, leading to understaffing, budgetary constraints and interference with the functioning of the libraries.

\subsubsection{Services}

Legislative libraries can decide what services to offer their clients. In most cases it is dependent on the resources and staff available. Despite small staff complements a wide variety of services are offered in the respective legislative library and research units. Core services such as reference services, newspaper clipping service, information service, access to Internet, and the availability of reading room facilities, are offered by all the libraries, with the exception of the Free State Provincial Legislative Library that does not offer Internet access, and the Eastern Cape Provincial Legislative Library that neither provides a newspaper clipping service nor an information service. The latter is offered by the reference service.

It was determined that some libraries do have the capacity to offer some technical services such as the videotaping, editing and dubbing of activities of importance to parliamentarians. Value-added service concerning newspaper clippings of issues of the day is offered on a regular basis in a variety of legislatures. The value of these services lies in the fact that the parliamentarian can be assured that the information is either kept available in the library for future reference, or that through the services offered they will be kept up to date of the latest events. Time spent on scanning newspapers themselves can thus be used for other important activities. 


\subsubsection{Collections}

Collections, with the exception of the Library of Parliament and the KwaZulu/Natal Provincial Legislative Library, are very small, contributing to problems of providing thorough information services. Even sources like journals that are good sources of current information, are in short supply in most of the libraries. A positive development is the fact that electronic sources are available, or subscribed to, in the majority of cases. Though computers for the parliamentarian's own access to these sources are not available in all the libraries, all staff members in the libraries do have access to networked computers. This facility allows for the utilization of the librarian as intermediary in the case of an electronic search. In the case of the Library of Parliament, Limpopo and North West Provincial Legislative Libraries, parliamentarians can utilize the networked computers. With the facilities available in the majority of the legislative libraries it is possible to fulfill to a huge extent the needs of the parliamentarians.

\subsubsection{Reading rooms}

Reading rooms where parliamentarians can sit down to either read the newspapers or does their research work are available in all the libraries. In some cases the rooms are very well utilized, while some libraries reported very little utilization.

\subsubsection{Marketing}

Marketing of the services offered is done in all the libraries. Though many different methods are used innovation seem to be lacking. In an environment where the clientele's information needs are at a premium, and it is of utmost importance for the well being of the whole nation that decisions be based on sound information, innovative methods need to be devised to attract attention to services and facilities offered. Especially since the services are available on the premises of the work environment it is even more important to be judged as a preferred information facility. To a great extent budget and staff allocation is closely related to utilization, making it imperative that services be fully appreciated and utilized. Simandjuntak (1996) points out that lack of understanding the business of the library results in rare increases in library funds to support the needs of the library. Marketing the services effectively will be no minor undertaking, especially with the time-constraints and workloads that parliamentarians experience. Innovation will ask for the utilization of different methods, other than the traditional methods of displays, fliers and newsletters, and should reach out to the parliamentarian in his/her immediate work environment, thus bringing the library services into their offices, and not expecting them to come to the library. Here electronic facilities could be utilized with great success.

\subsubsection{Library membership}

Only two libraries did not report any restriction placed on membership or services offered, i.e. the Eastern Cape and the North West Provincial Legislative Libraries, though from their service delivery it can be assumed that membership is restricted to parliamentarians only. This is also the case at the Library of Parliament, and the Western Cape Provincial Legislative Library. On arrangement members of the public such as researchers, academics and government officials can make use of the facility at the Library of Parliament, though no other services, other than providing access to information materials and making of photocopies, are provided.

The legislative library of Kwa-Zulu/Natal and the Free State Provincial Legislature follows a second model, that of the collection being available to the entire political class. Membership however only applies to parliamentarians.

\subsubsection{Preferred information formats}

As technology produces larger varieties of information formats so does an individual's preferences for a specific format change. To test whether this movement affected format preferences the libraries were asked to express their perceptions in this regard. The findings reflected a high preference for information to be provided in an oral format, specifically face-to-face and telephonically. This finding co-incided with the findings of Thapisa (1996). A much lower preference was expressed for materials in a print-based form, while e-mail communications were not seen as a strong preference. Audio-visual, audio and visual formats were perceived to be not preferred. This finding was a strong contradiction to the preferences expressed by the parliamentarians, who strongly preferred materials in print-based or digital format. Responses received from parliamentarians as reported earlier in this paper revealed that oral information provision was one of the least preferred options, even less than audio-visual and visual formats. From the findings it seems as if a communication gap exists between the libraries and their clientele as to the preferred media of information dissemination.

\subsubsection{Electronic services}

Though still far away from the ideal of providing all library services electronically to parliamentarians, the study has found that all the libraries are connected to a network providing them with either access to the Internet or to e-mail communications. This step enables electronic searches to be done, either on-line or off-line, and results to be communicated to the parliamentarians. The fact that most libraries subscribe to the services offered by SABINET provides the parliamentarians access to important current sources like the newspaper clipping service, indexed journal 
articles and full-text of the Bills and Acts promulgated by Parliament. Through Internet access the sources on the system can be utilized by both the parliamentarians and the librarians. As the majority of the respondents indicated having access to the Internet in their work or home environment it should not be a priority of the libraries to provide Internet access inside the library, except if the legislature does not provide networked computers to all their parliamentarians in their offices. The fact that $50 \%$ indicated that they do provide Internet access to parliamentarians inside the library is an indication that the work environment has not yet achieved this goal.

Utilization of a service is always a good indicator of the value put on the services offered. It was found that the majority made use of the legislative libraries, however a cautionary note has to be issued concerning the utilization of the services, as more than half of the respondents indicated that they seldom (49\%) or never (1 I\%) used the services. This indicates that less than half of the respondents felt confident about the value of the services delivered.

3.5 Proposal of a conceptual model for effective parliamentary information services

The study has shown that parliamentarians use a variety of information sources and systems to satisfy their information needs. The information sources and systems used range from informal sources such as oral sources to formal information systems such as libraries. Insight gained into the information-seeking behavior of the parliamentarians showed five trends emerging, i.e. those parliamentarians:

- commonly prefer to use their own information sources and expertise to satisfy the majority of their information needs

- often use an intermediary within their immediate work environment, i.e. their personal assistants to do their information searches for them

- utilize researchers, be they from a dedicated research unit within the Parliamentary structure, affiliated to the Library, or from within Party ranks

- utilize librarians or research assistants stationed within the library to find the needed information

- Visit the library in person to do their own information searches, with or without the assistance of the library staff. From the study it was clear that the parliamentarians have to cope with strenuous work programmes, leaving them with little time to effectively search unassisted through all the information sources, services and systems available to them, despite their stated preference for this option. Another hampering factor during the search process is the amount of unfiltered information that the parliamentarian could retrieve during a search strategy, leading to frustration and unnecessary stress. The options of utilizing the appropriate intermediaries as gatekeepers to filter the information used by the parliamentarians should therefore be seriously considered. Gate keeping allows for the filtering of information, thus providing the parliamentarian with relevant information. Currently, the gate keeping role, in the researchers' view, is done as illustrated in the model on the following page.

As indicated previously parliamentarians within their working environment use various methods to retrieve information from the available information sources, services and systems. Most notable is the employment of own skills and expertise to retrieve and access information (PIRSI). Personal searching involves direct access to information from the information environment. Access and utilization, however, can be influenced by various variables, e.g. psychological variables, source characteristics; role related/interpersonal variables and so on. The information environment includes formal, informal, oral and electronic information sources, services and systems (refer to Table 2.), and can include both information sources belonging to the parliamentarian, or information sources, -services and -systems accessible in the public and private domain.

However, for the information to be appropriate and relevant it needs to be reliable, accurate, understandable, comprehensive, close to the user, and current and in a format that is applicable to specific information need. As indicated, information received from the information environment is often of an unfiltered nature, providing information unable to satisfy the information need. It is especially information retrieved through the electronic medium that can cause a lot of frustration, as it is a time-consuming process resulting in a multitude of "hits", the majority of which might be unrelated to the information required.

A second strategy that is used is the utilization of intermediaries (PIRS2). This is often the case when parliamentarians work against deadlines, are too busy, or realize their lack of expertise to retrieve the necessary information. The intermediaries are normally within close proximity of the parliamentarians and could include individuals such as the parliamentary librarians (PL's), researchers from research units within the parliament (PR's), as well as the parliamentarians' personal assistants (PA's). As part of their information seeking skills these intermediaries can be expected to provide information that will satisfy the information need of the parliamentarian. Filtering (gate keeping) of information is thus essential as huge amounts of information, all of varying quality and appropriateness, are available. Filtering of information is part of a gatekeeper's daily activities, and indeed the professional information provider's role, making the gatekeeper ideally suited for the retrieval and dissemination of information to the parliamentarian. 


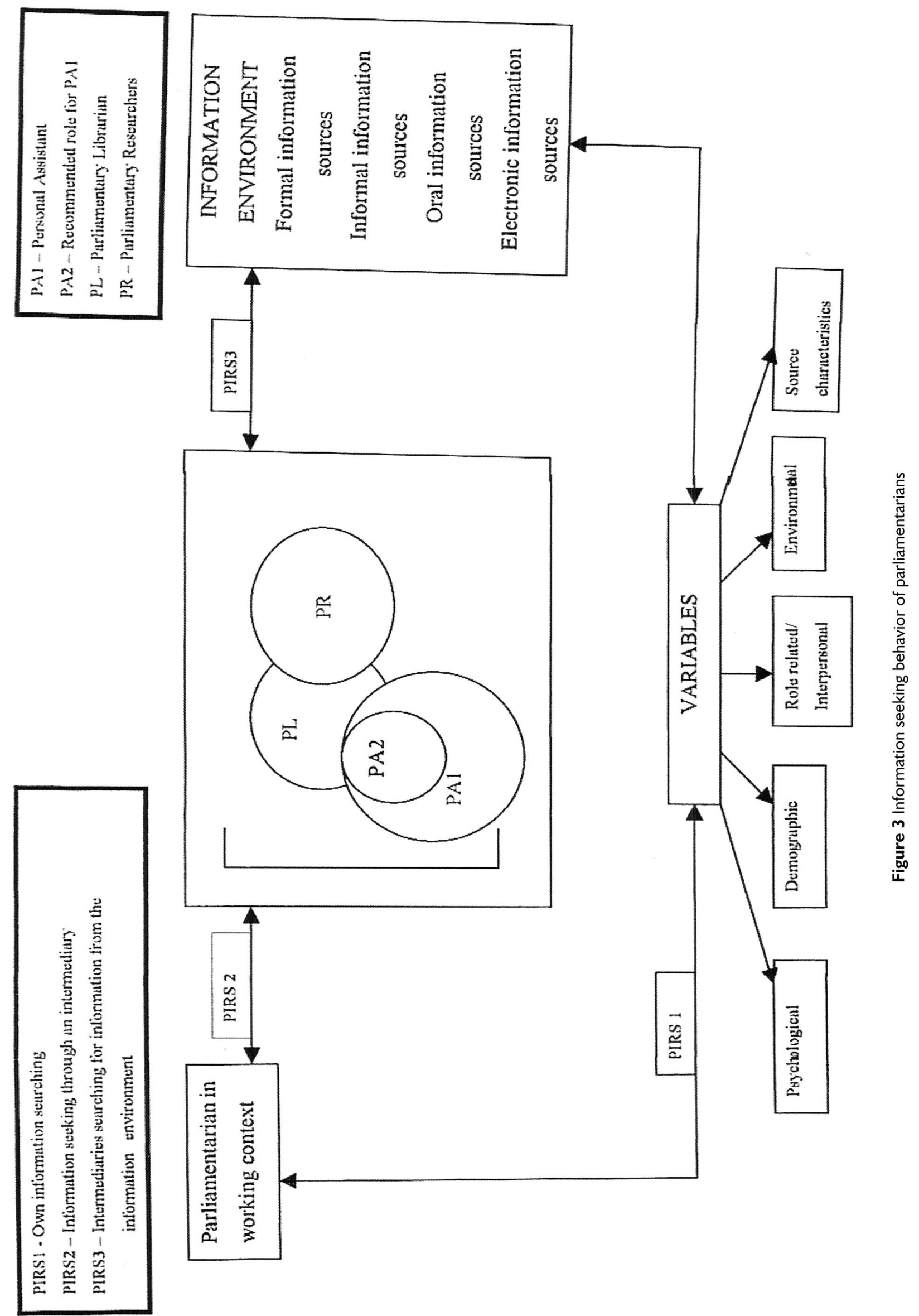

SA JnI Libs \& Info Sci 2005, 7I (2) 
Within the PIRS2 overlapping of information services seems to take place between the parliamentary librarian (PL), and the parliamentary researchers (PR) within the parliament. Overlapping of services mainly concerns the provision of research-related services. The role of the personal assistant (PAI) overlaps with the information services provided by the parliamentary librarians. Based on the perceived lack of information seeking, and analyzing skills of PAI, it is assumed that overlapping with the PR's do not take place.

However, it is noted that PAI is the most preferred intermediary and therefore it's role as gatekeeper needs more investigation. The skill to effectively filter information is only gained through training and experience, and this is not normally part-and-parcel of PAs training programmes. As trained and experienced human intermediaries/gatekeepers the PLs, as well as the PRs should be effective in filtering information. Based on this observation it is suggested that the role of $\mathrm{PAI}$ as information provider/gatekeeper should be minimized (PA2) and rather performed by those intermediaries qualified to do so.

The third information search that can take place is that between the intermediaries and the information environment (PIRS3). Though intermediaries sometimes are able to provide the requested information without consulting the information environment, the majority of information needs can only be satisfied through interaction with the information environment. The information retrieved through the information environment is often in unfiltered form, thus needing further filtering by the gatekeeper before the dissemination process can proceed.

\section{Conclusions}

This study observes that South Africa has a strong information sector that can support parliamentary information needs and services (see Mostert, 2004). For example Internet access (78\%) is widespread and higher than some countries such as UK, 73 \% (Serema, 1999) and Ghana, $14 \%$ (Alemna and Skouby, 2000). While the use of text/print based sources is still rated high, the use of electronic sources is rapidly increasing, almost matching that of print sources (see, tablel). Ironically, oral sources are used less than print and electronic sources of information as was expected. Observed further that although the use of electronic sources is increasing rapidly, access and use of the sources is still surrounded with technical problems originating from low bandwidth, limited ICT knowledge and skills for exploiting technology and inadequate knowledge of the potentials of the information searching and retrieval technology. It was also disturbing to find out that parliamentary libraries that are within the work environment of the parliamentarians and dedicated to fulfill their information needs, are underutilized perhaps due to inadequate marketing of their services, lack of creative and innovative information services or ignorance of the users of their information provision potential. Majority (75\%) of the parliamentarian's access information through personal sources while $62 \%$ use personal computers to access information. Interestingly, most of the parliamentarians have tertiary qualifications/education that contradicts what Thapisa (I996) found on African parliamentarians. This level of education might have contributed to a pattern of information seeking that varies with levels of education where higher use of information sources was prevalent among better educated parliamentarians and use of electronic sources rather than oral sources is high. The majority (70\%) of the parliamentarians conducted own searches, However, senior parliamentarians (52\%) e.g. cabinet ministers and parliamentary committee chairs relied more on human intermediaries, e.g. personal assistants, for information accessibility. However, the use of parliamentary librarians (31\%) and parliamentary researchers (35\%) who are professionally trained to provide information services was low. Although information is largely needed in a variety of domains, politics, governance and local and regional matters top the list of needs (see fig.2). We have also noted that parliamentary libraries lack strong coordination and resource support to fulfill their functions. Finally, we have recognized the complexity of information behavior among parliamentarians in relationship to human intermediaries (PL, PR and PA) in fig. 3 and propose measures how the information space can be further developed to improve information services. We propose an agenda for further development of parliamentary information services to include:

- Debating the proposed model of information seeking of parliamentarians (see fig.3)

- Underutilization of the parliamentary library

- Research e.g. future role and development of Personal Assistants

- Role of mobile phones in information seeking and retrieval

- The development of niche areas for the parliamentary library

\section{References}

Alemna, A.A. and Skouby, K.E. 2000. An investigation into the information needs and information-seeking behaviour of members of Ghana's legislature. Library Management, 2 I (5):235-240.

Behrens, S.J. 2000. Bibliographic control and information sources. $3^{\text {rd }}$ ed. Pretoria: Unisa Press.

Belkin, N.J. 1990. The cognitive viewpoint in information science. Journal of Information Science, 16:1 I- 15.

Belkin, N.J., Oddy, R \& Brooks, H. 1982. ASK for information retrieval. Journal of Documentation, 38(I):6I-7I. 
Boon, J.A. 1992. Information and development: towards an understanding of the relationship. South African Journal for Library and Information Science, 60(2):63-72.

Buckland, N. 199I. Information as thing. Journal for Information Science, 42(5):35I-360.

Burger, D ed. 2002. South Africa Yearbook 2002/03. $6^{\text {th }}$ ed. Pretoria: Government Communication and Information System.

Busha, C.H. \& Harter, S.P. 1980. Research methods in Librarianship: techniques and interpretation. San Diego: Academic Press.

Dervin, B. \& Nilan, M. 1986. Information needs and uses. Annual review of Information Science and Technology, 21: 3-33.

Ellis, D. 1989. A behavioural approach to information retrieval system design. Journal of Documentation, 45(3): $17 \mid-212$.

Gross, M. 200I. Imposed information seeking in public libraries and school media centers: a common behaviour? Information Research, 6(2): I-10. [Online] http://informationr.net/ir/6-2/paper 100.html. Accessed 24 January 2002.

Hagan, F.E. 2000. Research methods in criminal justice and criminology. $5^{\text {th }}$ ed. Boston: Allyn and Bacon.

Hjørland, B. 1998. Theory and metatheory of Information Science: a new interpretation. Journal of Documentation, 54(5): 606621 .

Ingwersen, P. 1992. Information retrieval interaction. $6^{\text {th }}$ ed. London: Taylor Graham

Itoga, M. 1992. Seeking understanding beneath the unspecifiable: an alternative framework for mapping information needs in Communication. Libri, 42: 330 -343.

Kimbunga, T.M. 1996. The role of parliamentary library and research services in multi-party Tanzania. Literature review, 45(6): 18 $-24$.

Krikelas, J. 1983. Information-seeking behaviour: patterns and concepts. Drexel Library Quarterly, 19:5-20.

Kulthau, C. 1993. A principle of uncertainty for information seeking. Journal of Documentation. 49(4):339 - 355.

Kulthau, C 1991. Inside the search process: information seeking from the user's perspective. Journal of the American Society for Information Science. 42(5): 36I - 37I.

Leckie, G.J., Pettigrew, K.E' and Sylvian, C. 1996. Modeling the information seeking of professionals: a general model derived from research on Engineers, Health Care Professionals and Lawyers. Library Quaterly, 66(2):161 - 193.

Madden, A. 2000. A definition of information. Aslib Proceedings, 52(9):343-349.

Marcella, R, Carcary, I and Baxter, G. 1999. The information needs of United Kingdom Members of the European Parliament (MEPs). Library Management, 20(3): 168- 78.

McCreadie, M \& Rice, R.E. 1999. Trends in analysing access to information. Part I: cross-disciplinary conceptualisations of access. Information Processing and Management, 35:45-67.

Mostert, B.J. 2004. Parliamentary information sources, systems and services in South Africa and the role of parliamentary libraries in information provision. (Ph.D.-thesis). KwaDlangezwa: University of Zululand.

Muller, C.F.J. ed. 1968. 500 Jaar Suid-Afrikaanse geskiedenis. Pretoria: Academia.

Neuman. W.L. 2003. Social research methods: qualitative and quantitative approaches. $5^{\text {th }}$ ed. Boston: Pearson education.

Orton, R, Marcella, R and Baxter, G. 2000. An observational study of the information seeking behaviour of Members of Parliament in the United Kingdom. Aslib Proceedings, 52(6):207 - 217.

Research findings of Library Questionnare. 1997. Parliament Annexures. 1997. No. 234 - 244.

Rohde, N.F. 1986. Information needs. Advances in Librarianship, 14:49-73.

Sarantakos, S. 1998. Social research. $2^{\text {nd }}$ ed. New York: Palgrave.

Serema, B.C. 1999. Matching MP's information needs and information services in the House of Commons. Library Management, 20(3): $179-189$

Simandjuntak, A. 1996. The Association of Parliamentary Librarians of Asia and the Pacific: constraints, challenges, but very good cooperation among its members. [Online]. http://www.ifla.org?VII/s3/conf/I pacif e.htm. Accessed 25 July 200 I.

Smith, J.G. 1991. Theoretical framework of studying the communication of scientific information in a defined community. South African Journal of Library and Information Science, 59(2):84-94.

Stonier, T. 1991. Towards a new theory of information. Journal of Information Science, 17:257-263.

Thapisa, A. P. N. 1996. "Legislative Information Needs of Indigenous Parliamentarians in Botswana and Impact of effective decision making". International Information \& Library Review, 28: 203-232.

Turnbull, D. (n.d) Augmenting information seeking on the World Wide Web using collaborative filtering techniques [Online]. http:// donturn.fis.utoronto.ca/research/augmentis.html. Accessed 25 January 2002.

Van Lill, C. 2000. A model for studying users' information needs and use. South African Journal of Library and Information Science, 67(I):38-49.

Wilson, T.D. 1999. Models in information behaviour research. Journal of documentation, 55(3):249 - 270.

Wilson, T.D. 1997. Information behaviour: an interdisciplinary perspective. Information Processing and Management, 33(4):55I 572.

Wilson, T.D. 198I. On user studies and information needs. Journal of documentation, 37(I):3 - 15.

\section{Declaration and acknowledgement}

The original version of this paper was presented at the ProLISSA Conference in Pretoria on 28-29th October 2004 (see http://www.dissanet.com). The University of Zululand Research Committee is acknowledged for funding this research. 